\title{
Long-Term Partial Remission of Autolmmune Thrombocytopenia in a Patient Treated with the Anti-Tumor Necrosis Factor-Alpha Antibody Infliximab for Refractory Fistulizing Crohn's Disease
}

\author{
Thomas M. de Rossi ${ }^{a} \quad$ Norbert Krauss $^{a}$ Reinhard E. Voll ${ }^{b} \quad$ Andreas Nägel $^{a}$ \\ Michael Weidenhiller ${ }^{\mathrm{a}}$ Peter C. Konturek ${ }^{\mathrm{a}}$ Eckhart G. Hahn ${ }^{\mathrm{a}}$ Martin Raithel $^{\mathrm{a}}$ \\ Departments of ${ }^{\mathrm{a}}$ Internal Medicine I, and ${ }^{\mathrm{b}}$ Internal Medicine III, Friedrich-Alexander University of \\ Erlangen-Nuremberg, Erlangen, Germany
}

\section{Key Words}

Anti-tumor necrosis factor antibody • Crohn's disease • Immune thrombocytopenia (Werlhof's disease)

\begin{abstract}
Background: Up to the present date, the treatment of recurrent chronic fistulas occurring with Crohn's disease represents a challenging task for both internists and surgeons alike. Methods: Conservative methods of treatment using steroids, dietotherapy, antibiotics or immunosuppressive agents are not particularly effective in treating fistulas. Treatment with anti-tumor necrosis factor- $\alpha$ (TNF $\alpha$ ) antibodies results in more remissions of fistulas. However, its use requires appropriate medical experience and causes substantial costs. Surgical procedures such as fistula sanitation or protective ileostomy are often obfuscated by the recurrence of the condition. The efficiency of anti-TNF $\alpha$ antibodies for the treatment of active Crohn's disease has been evidenced through several multicenter, double-blind, placebo-controlled studies. Results: Here we report the successful antiTNF $\alpha$ treatment of a patient suffering from chronic, fistulizing, therapy-resistant Crohn's disease and a concomitant
\end{abstract}

chronic autoimmune thrombocytopenia. The chimeric antiTNF $\alpha$ antibody infliximab markedly reduced the disease activity of Crohn's disease, and, in addition, substantially increased the platelet counts. After infliximab application, no other treatment of autoimmune thrombocytopenia was required. After infliximab therapy, autoantibodies to dsDNS could be observed. However, there were no signs of a lupuslike disease. Conclusion: This report indicates a favorable therapeutic response of autoimmune thrombocytopenia associated to Crohn's disease.

Copyright $\odot 2008$ S. Karger AG, Basel

\section{First Diagnoses, Patient's History and Findings}

A 41-year-old patient with Crohn's disease (CD, morbus Crohn) and idiopathic autoimmune thrombocytopenia (morbus Werlhof/Werlhof's disease) was first diagnosed with CD in 1989. Back then, a segmental involvement of the duodenum and ileum as well as a proctosigmoiditis were observed. Despite the therapy with 5-aminosalicylate, steroids (Decortin $\mathrm{H}^{\circledR}$ ) and metronidazol, anal abscesses required surgical interventions in 1989 and 2001.

\section{KARGER}

Fax +41613061234 E-Mail karger@karger.ch www.karger.com
(C) 2008 S. Karger AG, Base

0012-2823/08/0784-0195\$24.50/0

Accessible online at:

www.karger.com/dig
Thomas de Rossi, MD, Functional Tissue Diagnostics

Department of Internal Medicine I, University of Erlangen-Nuremberg

Ulmenweg 18, DE-91054 Erlangen (Germany)

Tel. +49 91318535 000, Fax +49 91318535152

E-Mail Thomas.deRossi@uk-erlangen.de 


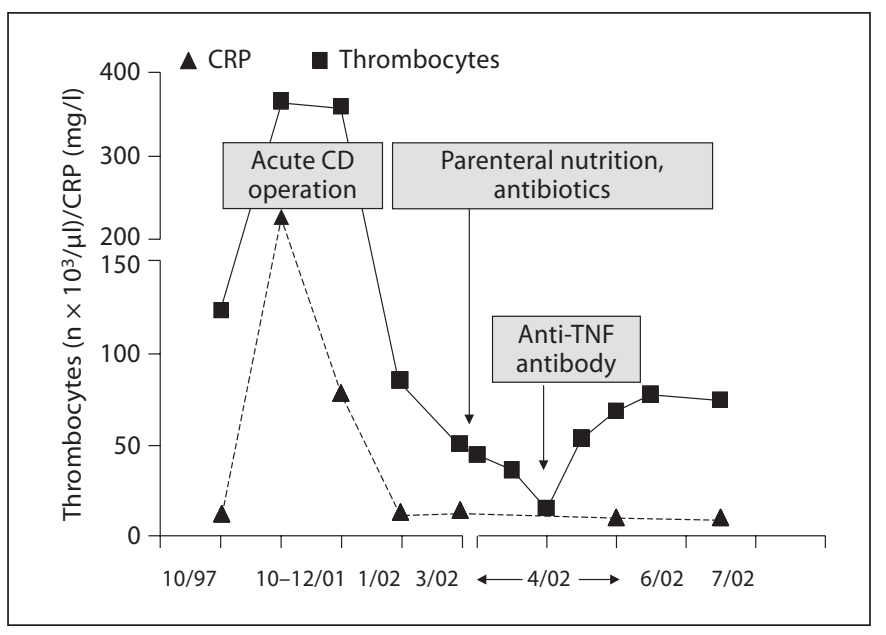

Fig. 1. Course of $\mathrm{CD}$ and associated autoimmune thrombocytopenia illustrated on the basis of thrombocytes and the C-reactive protein as a serological inflammatory marker. Upon first diagnosis of CD in 1997, normal thrombocyte values were determined. Although autoimmune thrombocytopenia was already diagnosed in 1999, normal thrombocyte values existed during the acute inflammatory phase at the end of 2001 (marked by high inflammatory activity). Thrombocytopenia manifested itself only after initial, postoperatively induced remission at the beginning of 2002 . Although a fistula system was detected in April 2002, the thrombocytopenia with an amount of only 13,000 thrombocytes/ $\mu$ l could be successfully treated with a single dose of infliximab.

To remove multiple stenoses, partial resection of the small intestine over a length of $120 \mathrm{~cm}$ had to be performed in June 1996. During the period from May 1998 to April 1999, the patient was treated with azathioprine up to $150 \mathrm{mg} / \mathrm{d}$. However, no obvious beneficial influence was noticed on the course of the disease. Due to decreasing thrombocyte counts and azathioprine inefficiency, the application of azathioprine was stopped in April 1999. Despite the discontinuation of the azathioprine treatment, thrombocyte counts remained low $(36,800-$ $54,000 / \mu \mathrm{l})$. Hematological investigation of the low thrombocyte levels resulted in the diagnosis of autoimmune thrombocytopenia suggesting Werlhof's disease. This diagnosis was concluded from the results of an iliac crest biopsy and the presence of platelet-bound auto-antibodies of the rare IgM type in the patient's serum $[1,2]$. There was no evidence of heparin- or drug-associated thrombocytopenia or heparin-induced thrombocyte activation including the risk of thrombosis (HIT II). The thrombocyte counts of this patient are shown in figure 1 .

In autumn 2001, the patient was admitted to the hospital because of a recent flexion contraction of the hip and hip pains. Diagnostic assessment discovered a highly florid CD with covered perforation of the ileum and abscesses in the right hypogastrium and the adjacent pelvic muscles. Initially, percutaneous abscess drainage was attempted and, subsequently, definite surgical abscess removal from the psoas and the right iliac muscle as well as a right hemicolectomy with ileoascendostomy were performed. Perioperatively, a mild allergic transfusion reaction to the administration of fresh-frozen plasma occurred. After surgery, medical rehabilitation followed, and the patient went slowly into remission until spring 2002.

In April 2002, the 41-year-old patient presented again with $12-15$ watery to semiliquid stools, which were sometimes bloody, accompanied with flatulence and an inflamed anal region (condition after known perianal fistulas). The disease activity index showed a Crohn's Disease Activity Index (CDAI) of 206 points indicating high activity of $\mathrm{CD}$. The medication at admission was hydrocortisone acetate - rectal foam (Colifoam ${ }^{\circledR}$ Foam) - and Saccharomyces boulardii capsules (Perenterol ${ }^{\circledR}$ capsules).

Physical examination revealed a patient with pale skin; the patient's height was $173 \mathrm{~cm}$ and his body weight was $69 \mathrm{~kg}$. His liver was palpable approximately $3 \mathrm{~cm}$ below the right costal arch. No resistance was found on the abdomen. Circulatory parameters were normal with a blood pressure of RR 110/80 $\mathrm{mm} \mathrm{Hg}$ and a heart beat frequency of $94 / \mathrm{min}$. The proctologic examination clearly showed a red inflamed anal region, multiple scar regions as well as a painful anal canal stenosis leaving only just a fingerwidth passage. Despite the urgent suspicion of an anal CD manifestation, macroscopically, no visible fistula openings could be detected.

\section{Laboratory Parameters, Clinical and Apparative Diagnostics}

In spite of the above-described clinical symptoms of activity, only a moderate systemic inflammatory activity could be determined in April 2002. Hemoglobin was 14.2 $\mathrm{g} / \mathrm{dl}$, hematocrit $39 \%$, leukocyte count was $9,100 / \mu \mathrm{l}$, and thrombocyte count was $51,000 / \mu l$ at the time of admission. The further course of thrombocyte counts is detailed in figure 1 . Slightly elevated were the concentrations of CRP with $12 \mathrm{mg} / \mathrm{l}$ (norm $<5 \mathrm{mg} / \mathrm{l}$ ) and the acidic $\alpha_{1}$-glucoprotein with $1,336 \mathrm{mg} / \mathrm{l}$ (norm $<1,200 \mathrm{mg} / \mathrm{l}$ ); ferritin serum concentrations were decreased with $12 \mathrm{ng} / \mathrm{ml}$ indicating an iron deficiency. The concentration of $\mathrm{Zn}^{-}$ was lowered to $44 \mu \mathrm{g} / \mathrm{dl}$ (normal $72-115 \mu \mathrm{g} / \mathrm{dl}$ ) and the 
concentration of vitamin $\mathrm{D}_{3}$ to $12.9 \mathrm{ng} / \mathrm{ml}$ (norm $20-120$ $\mathrm{ng} / \mathrm{ml})$.

Stool bacteriology was assessed 3 times without detecting any pathological findings.

The immunologic parameters showed normal values for $\operatorname{IgG}, \operatorname{Ig} \mathrm{A}$ and $\operatorname{IgM}$, whereas IgE was distinctly raised to $319 \mathrm{U} / \mathrm{ml}$, in keeping with the patient suffering from atopic dermatitis and multiple allergies: allergic rhinoconjunctivitis caused by pollen of rye and grass and food allergies toward nuts, carrots, citrus fruits and cabbage varieties. Determination of antineutrophil cytoplasmatic antibodies (c- and p-ANCA) was negative. Before infliximab therapy, the serum tumor necrosis factor- $\alpha$ (TNF $\alpha)$ concentration elevated to $16.5 \mathrm{pg} / \mathrm{ml}$ (normal range 0.1 $8.1 \mathrm{pg} / \mathrm{ml})$.

With regard to the planned anti-TNF $\alpha$ antibody treatment, a chest X-ray as well as a tuberculin skin test (Mendel-Mantoux test) were performed and showed no evidence of mycobacterial infection. Abdominal sonography pictured inconspicuous intra-abdominal organs, with the exception of a thickened intestinal wall of $5 \mathrm{~mm}$ diameter within the sigmoid area.

Due to the patient's history of perianal fistulas, an inflamed stenotic anal canal and previous perianal abscesses, we conducted an NMR tomography of the minor pelvis. At the site of a previous abscess in the right psoas muscle, a thin fox-earth-like fistula system was detected, extending from the left perianal tissues toward the cranial direction, but also approaching the sphincter muscle while passing at the right and dorsal site of the prostate. However, this fistula system did not open either toward the skin or toward the intestines. In front of the sacral bone, a small accumulation of fluid of $5 \mathrm{~mm}$ diameter was detected, most likely resembling an abscess formation.

Colonoscopy showed an end-to-end ileoascendostomy with a moderate anastomositis and ileitis, whereas the mucosa of the transverse colon upward to the sigmoid appeared normal. Within the distal sections of the rectum, however, a florid proctitis with erosions, fibrin deposits and bleeding were observed. Histologically, a chronic ileitis was diagnosed, showing giant-cell granulomas, lymphangiectasia and, in addition, a pronounced chronic colitis with superficial erosions, ulcers and bleeding into the rectum.

Determination of the bone density indicated an osteopenia of the lumbar vertebral column and the femur achieved a T-score of -1.6 ( $87 \%$ of the bone density of young adults) and a T-score of -1.5 ( $82 \%$ of the bone density of young adults), respectively.

Autoimmune Thrombocytopenia with Infliximab Therapy for CD

\section{Diagnosis, Further Therapeutic Strategies and Progress}

Based on the evaluations as detailed above, the following diagnoses were obtained at the end of April 2002:

(1) CD with a closed fox-earth-like fistula system, perianal left and chronic active ileitis, and proctitis in a 41-year-old patient, who had previously undergone right hemicolectomy, partial resection of the small intestine and recurrent perianal and abdominal abscesses in the period from 1989-2001.

(2) Autoimmune thrombocytopenia since 1999, possibly related to $\mathrm{CD}$.

(3) History of a mild allergic transfusion reaction in 2001.

(4) Atopic dermatitis, allergic rhinoconjunctivitis with pollenosis as well as hypersensitivity to grasses, nuts, carrots, cabbage, celery and citrus fruits.

So far, therapies with mesalazin tablets (Pentasa ${ }^{\circledR}$ ), metronidazol $\left(\right.$ Clont $^{\circledR}$ ), mesalazinklysma (Salofalk ${ }^{\circledR}$ ) as well as azathioprine (Imurek ${ }^{\circledR}$, from $5 / 98-4 / 99$ ), hydrocortisone acetate - rectal foam $\left(\right.$ Colifoam $\left.{ }^{\circledR}\right)$-, Saccharomyces boulardii (Perenterol ${ }^{\circledR}$ ) and repeated oral glucosteroid treatments $\left(\right.$ Decortin ${ }^{\circledR}$ ) failed to induce a remission, although occasionally, they caused complications. Hence, treatment with the anti-TNF $\alpha$ antibody infliximab was initiated, mainly to sanitize the fistulas [3]. In order to eliminate suspected bacterial infections within fistulas and the small presacral fluid accumulation before anti$\mathrm{TNF} \alpha$ treatment, antibiotic therapy with ciprofloxacin $\left(\right.$ Ciprobay $\left.{ }^{\circledR}\right) 2 \times 400 \mathrm{mg}$ i.v. and metronidazol $\left(\right.$ Clont $^{\circledR}$ ) $3 \times 500 \mathrm{mg}$ i.v. was performed for 2 weeks. In addition, the patient was subjected to parenteral nutrition (functional enteric exclusion) in order to remove possible focal infections or abscesses before the infliximab therapy.

Antibiotic treatment and parenteral nutrition caused a first decline in disease activity and regression of the fistula system (fig. 2), when the course of illness was complicated through a dangerous drop in the number of thrombocytes to $13,000 / \mu l$. Due to an acute risk of bleeding, we considered to cancel or postpone the infliximab administration and to treat immune thrombocytopenia with high-dose glucosteroids and/or high-dose intravenous immunoglobulins [1,2]. Similar to some other forms of autoimmune diseases, such as rheumatoid arthritis, spondylarthropathies, autoimmune hemolytic anemia and lupus nephritis, there is evidence that TNF $\alpha$ is also involved in the pathogenesis of chronic autoimmune thrombocytopenia [4-6]. Since few cases of successful treatment of immune thrombocytopenia with anti-

Digestion 2008;78:195-200 


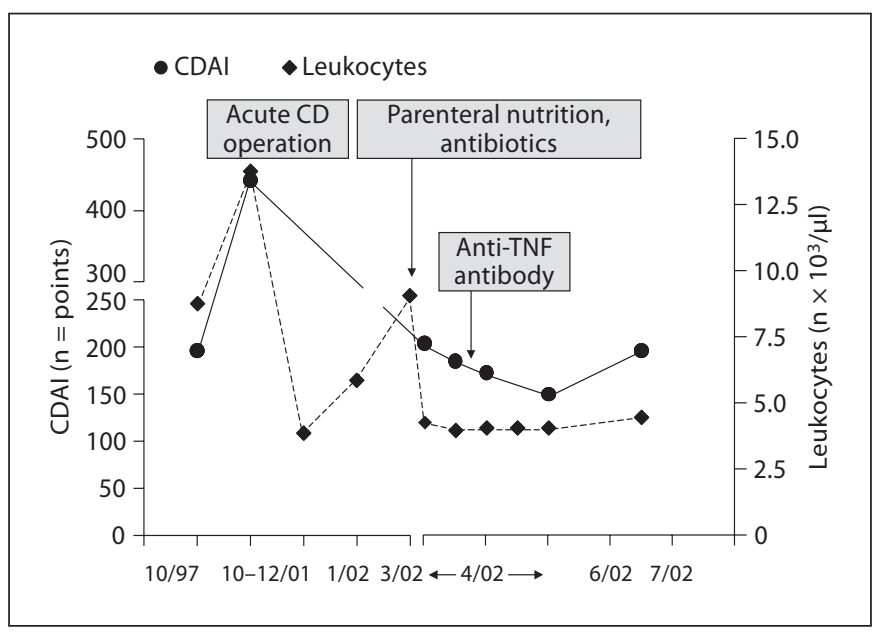

Fig. 2. Course of $\mathrm{CD}$ and associated autoimmune thrombocytopenia illustrated on the basis of leukocytes and the CDAI according to Best. At the end of 2001, leukocytosis was observed during the acute state of CD. Otherwise, the leukocyte levels in April 2002 , when the distinct thrombocytopenia of 13,000/ $\mu$ l occurred, and during the course of the disease were normal. The existence of an isolated thrombocytopenia in conjunction with a normal leukocyte level is regarded as a typical finding of immune thrombocytopenia and argues against metronidazol-induced thrombocytopenia.

TNF $\alpha$ antibodies have been reported, we applied $350 \mathrm{mg}$ infliximab (corresponding to $5 \mathrm{mg}$ infliximab/kg body weight) as intravenous infusion over a period of $2 \mathrm{~h}$. Before infliximab infusion, the patient received intravenous injections of $250 \mathrm{mg}$ prednisolon (SoluDecortin $\mathrm{H}^{\circledR}$ ) and $2 \mathrm{mg}$ clemastin $\left(\right.$ Tavegil ${ }^{\circledR}$ ). The infliximab infusion was well tolerated by the patient, and the thrombocyte counts increased from $13,000 / \mu \mathrm{l}$ to $51,000 / \mu \mathrm{l}$ within $12 \mathrm{~h}$ after infusion (fig. 1). The thrombocyte counts continued to increase during the following days and then remained stable at concentrations of approximately $70,000 / \mu 1$ for more than 54 weeks without any further therapeutic interventions for immune thrombocytopenia.

In contrast to the rapid and long-lasting increase of thrombocytes, the CDAI showed only a moderate decrease to nearly 150 points within 4 weeks after the first application of infliximab, and the disease activity of $\mathrm{CD}$ increased again thereafter. Hence, the second scheduled infliximab infusion had to be applied as early as 6 weeks after the first application to control the activity of fistulizing $\mathrm{CD}$. The thrombocytes remained stable at a concentration of approximately $72,000 / \mu \mathrm{l}$. Within $12 \mathrm{~min}$ after starting the second infliximab infusion, a serious anaphylactoid reaction with generalized urticaria, seri- ous dyspnea, hypotonia and apathy occurred, inspite of pretreatment with $250 \mathrm{mg}$ prednisolone and clemastine, as it was performed at the first infliximab application. The patient required intensive care including oxygen administration, volume substitution, a single intravenous dose of prednisolone ( $250 \mathrm{mg}$ SoluDecortin $\mathrm{H}^{\circledR}$ ) as well as histamine receptor- 1 and -2 antagonists for 1 day.

The patient refused further infliximab therapy and preferred surgical fistula sanitation and a protective ileostomy.

The thrombocyte concentration remained stable at 72,000 thrombocytes/ $\mu$ l over a period of more than 12 months after the first treatment with infliximab, as shown in figure 1. Also, no further treatment for the immune thrombocytopenia was required. Possibly, the application of $250 \mathrm{mg}$ prednisolone before each infliximab treatment may have had a positive influence on the thrombocyte level. However, the rapid increase of the thrombocyte numbers within just $12 \mathrm{~h}$ and the alleged long-lasting therapy effect of more than 54 weeks argue strongly against a glucosteroid effect. Only $15-20 \%$ of patients experience long-term remission responses to glucosteroid monotherapy. Hence, the long-term partial remission of immune thrombocytopenia in this patient was most likely due to infliximab treatment, although concomitant glucosteroids may have contributed to increase the thrombocyte counts. Such a very rapid increase in the number of thrombocytes within several hours, as reported here after infliximab infusion, cannot be achieved with steroid therapy (increase of thrombocytes after 1-4 weeks), and is even very uncommon after highdose intravenous immunoglobulin therapy, upon which platelet counts usually increase within 1-7 days.

\section{Discussion}

CD with concomitant autoimmune thrombocytopenia is a rather rare event for which only few information exists in medical literature [12]. However, CD complicated by immune thrombocytopenia may cause a potentially life-threatening situation for the individual patient, if in the course of $\mathrm{CD}$ spontaneous bleeding occurs, or if emergency operations are necessary. In addition, the coincidence of both diseases requires special precautions to be taken by the medical staff. For diagnostic purposes, biopsies need to be taken in CD. For therapeutic reasons, balloon dilatations of stenoses may cause tears, which are accompanied by an increased risk of bleeding, if the patient also suffers from thrombocytopenia. 
In the described case here, the nadir of thrombocytes occurred during intravenous treatment with the antibiotics metronidazol and ciprofloxacin as well as during parenteral nutrition via a central venous catheter. Hence, pre-existing immune thrombocytopenia might have been aggravated by a bone marrow depressive effect caused by metronidazol $[1,2,7]$. However, the fact that the leukocyte and erythrocyte counts remained normal argues against a relevant drug-induced myelosuppression (fig. 1 and 2) [1, 2, 7].

Through the possibility to neutralize the soluble and membrane-bound TNF $\alpha$ with the monoclonal chimeric antibody [3, 4], an attractive method of treatment can be suggested for both diseases. Herewith, not only is an alleviation of CD possible in over two thirds of patients [3, 8], but also a clinically relevant elevation of thrombocyte numbers in immune thrombocytopenia. Considering the possible spectrum of side effects, infliximab therapy should not be performed to treat thrombocytopenias of a different origin, because potentially infectiological or septic complications induced by anti-TNF $\alpha$ antibodies could lead to further consumption of thrombocytes, and then potentially cause serious secondary bleeding complications.

Chronic autoimmune thrombocytopenia (IgG or IgM serum auto-antibody) is an exception with regard to the required minimal amount of thrombocytes in the blood, because in this case, the thrombocytopenia itself is partially conveyed through the circulating TNF $\alpha$ (e.g. activation of cytotoxic $\mathrm{T}$ cells, stimulation of phagocytosis) [4-6]. In contrast to the acute form of autoimmune thrombocytopenia, the chronic form often does not respond to steroids (only about $15-20 \%$ of treated patients respond $[1,2])$, so that further established therapies, including azathioprine and high-dose intravenous immunoglobulin, are considered before a possible splenectomy $[1,2]$. Since the patient described here developed thrombocytopenia during azathioprine treatment, only the expensive immunoglobulin therapy could have been chosen as a standard therapy (e.g. $0.4-1 \mathrm{~g} / \mathrm{kg}$ body weight over a period of 5 days) $[1,2]$. Alternative therapies include the treatment with anti-D antibodies for rhesuspositive patients or the administration of danazol [2].

Another anti-TNF $\alpha$ antibody (etanercept) has been ineffective in patients with $\mathrm{CD}[9,10]$, but a complete recovery from refractory immune thrombocytopenic purpura in 3 patients treated with etanercept could be shown [11].

For this patient with CD, the required amount of standard intravenous immunoglobulin treatment at the low dosage of $0.4 \mathrm{~g} / \mathrm{kg}$ body weight per day adds up to a total of approximately $28 \mathrm{~g}$ immunoglobulin a day $[1,2]$. This amount of immunoglobulins causes daily treatment costs of approximately EUR 2,546 (calculated for sandoglobulin) [12]. Hence, 5 days of a standard intravenous immunoglobulin therapy would result in costs of EUR 12,730 to treat immune thrombocytopenia. Since intravenous immunoglobulin therapy for $\mathrm{CD}$ has been ceased in the last years due to limited benefit [7], the usage of anti-TNF antibodies for the treatment of immune thrombocytopenia, especially combined with $\mathrm{CD}$, becomes an efficient and relatively cost-efficient treatment $(350 \mathrm{mg}$ infliximab; EUR 3,333) $[1-3,12]$, which in our reported case achieved a long-term rise to approximately $70,000 / \mu \mathrm{l}$ thrombocytes after one application only (fig. 1).

Thrombocytopenia due to auto-antibody formation does not represent a contraindication for the administration of infliximab; instead, as illustrated with this case, it can be applied as a valuable and cost-efficient treatment for both CD and immune thrombocytopenia. This is particularly the case when alternative therapies, such as steroids and azathioprine, are not effective, or when expensive substances like immunoglobulin and chemotherapeutic agents, such as cyclophosphamide with undesirable side effects, should be avoided.

So far, this case report contains an important indication for the treatment of morbus Werlhof thrombocytopenia with infliximab, if in a gastroenterological nonseptic/infectious emergency situation (e.g. acute bleeding, preparation for surgical procedures) a very quick increase of thrombocytes becomes necessary. Further observations and systematic studies with regard to morbus Werlhof treatment with infliximab are needed to confirm this.

References

Digestion 2008;78:195-200 199
1 Aulitzky WE: Erkrankungen der Thrombocyten; in Lehnert H, Schuster HP (eds): Innere Medizin. Stuttgart, Ferdinand Enke Verlag, 1998, pp 1058-1062.

2 Lechler E: Hämorrhagische Diathesen; in Classen M, Diehl V, Kochsiek K (eds): Innere Medizin, 3. Aufl. München, Urban \& Schwarzenberg Verlag, 1994, pp 271-273.

3 Bickston St, Cominelli F: Treatment of Crohn's disease at the turn of the century. $\mathrm{N}$ Engl J Med 1998;339:401-402.

4 Kuloğlu Z, Kansu A, Demirçeken F, Ileri T, Ertem M, Girgin N: The association of chronic recurrent immune thrombocytopenic purpura and Crohn's disease. Inflamm Bowel Dis 2005;11:950-951. 
5 Eigler A, Loher F, Endres S: Suppression der Synthese des Tumornekrosefaktors. Internist 2001;42:28-34.

6 Cope AP: Regulation of autoimmunity by proinflammatory cytokines. Curr Opin Immunol 1998; 10:669-676.

7 Cooke A, Wraith DC: Immunotherapy of autoimmune disease. Curr Opin Immunol 1993;5:925-933.
8 Goebell H, Ewe K, Malchow H, Koelbel CH (eds): Inflammatory Bowel Disease: Progress in Basic Research and Clinical Implications. Lancaster, Kluwer Academic Publishers, 1991.

9 Wittig BM, Duchmann R, Stallmach A, Zeitz M: Modulation von Zytokinen bei chronisch entzündlichen Darmerkrankungen. Internist 2001;42:47-54.

10 Sandborn WJ, Hanauer SB, Katz S: Etanercept for active Crohn's disease: a randomized double-blind, placebo-controlled trial. Gastroenterology 2001;121:1088-1094.
11 McMinn JR Jr, Cohen S, Moore J, Lilly S, Parkhurst J, Tarantino MD, Terrell DR, George JN: Complete recovery from refractory immune thrombocytopenic purpura in three patients treated with etanercept. Am J Hematol 2003;73:135-140.

12 Rote Liste 2003: Frankfurt/Main, Editio Cantor Verlag, 2003. 